\title{
Book Review_Inside Teaching: How to Make a Difference for Every Learner and Teacher
}

\author{
Rod Galloway $^{1}$ \\ ${ }^{1}$ Principal, George Street Normal School, Dunedin, New Zealand \\ Correspondence: Rod Galloway, George Street Normal School, 989 George Street, Dunedin 9016, New Zealand. \\ E-mail: rod@georgestreet.school.nz
}

Online Published: August 28, 2018 doi:10.5539/ies.v11n9p90 URL: https://doi.org/10.5539/ies.v11n9p90

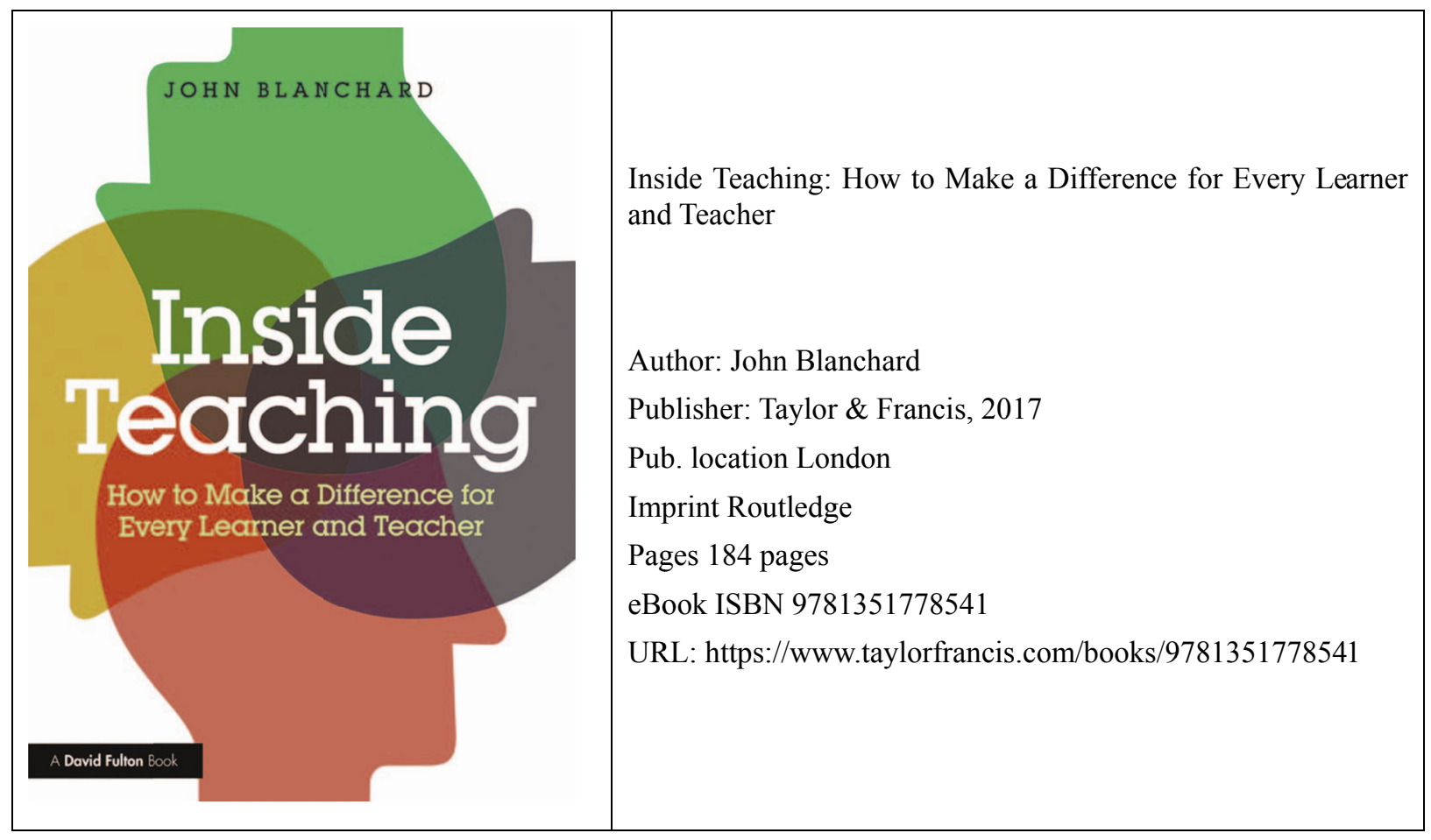

\section{Summary Review and Endorsement}

In the introduction to his book "Inside Teaching", John Blanchard describes his intention of offering the reader an opportunity to: "take stock, consider practical options, plan, experiment, reflect and still have time and energy to lead your life." In drawing together his own experiences as a teacher and teacher educator, as well as other knowledgeable experts, Blanchard presents a thoughtful collection of teaching and learning topics that achieve his goal. While no theme in this book is covered in depth, and at times is presented as a personal view without reference to the relevant research base, there is enough content, presented with examples and authoritative comment, to interest and inform readers with different educational experience. Although a relatively short book, this is a highly practical manual of ideas, ready for immediate adoption. Inside Teaching is destined to become a popular and worthy addition to the reading lists of those new to teaching, as well as those facilitating professional development or teaching inquiries.

\section{Body of the Review}

The strength of this book can be summed up in two aspects, evident throughout three sections containing twenty short chapters. First, Blanchard's writing style is concise and easy-to-read. Topics are covered in such a way that they can be used in isolation, allowing individual teachers or teams to focus on one area of interest. Each chapter is separated into sections that pose a key educational question (e.g., "how can you engage with and guide your pupils' motivation?"), is punctuated by lists and tables and concludes with a summary of main points and a set of useful 
references. In total, twenty of these questions are posed throughout the book personalising each topic (e.g., how will you ...) and assisting the reader to focus on strategies that could be implemented. In working through each of these sections, Blanchard is careful to define, explain and provide examples of educational terms and ideas. This emphasis on informing and guiding the reader contributes to an ease of understanding as Blanchard considers the student at the centre of any teaching enterprise (Part 1), the teacher as the agent of change, (Part 2), and continuing to learn about teaching (Part 3).

Secondly, topics discussed are potentially applicable to many different teaching and learning contexts, in any country, and with any student age-group. For the classroom teacher and, perhaps in particular, a beginning teacher, the chapters in Part 1 of the book focussing on knowing and understanding the learner, serve as a useful overview of student engagement and motivation. The last chapter in this section (chapter 6), for example, highlights some essential understandings relating to the important topic of student agency. Suggested strategies to determine what students can do to take charge of their learning are designed to be easily implemented and enhance student voice and action in classroom programmes.

Equally useful are the chapters in Part 2 that describe and discuss teaching and learning topics such as homework and providing effective feedback. On page 65 , for example, the question, "when do you use whole-class teaching, and when do your pupils work in groups or teams or individually?", is answered by providing reasons why each learning setting would be more appropriate. Such succinct summaries are useful and memorable.

As a school principal, the reviewer found the ideas reported in Part 3 such as, professional development (chapter 17), observing lessons (chapter 18), and appraisal systems (chapter 19), to be concise reminders of best practice. For this reviewer, Blanchard leaves his most interesting set of suggestions until the last chapter. The use of checklists (also referred to as protocols, standard procedures and key things to do) is presented as a strategy to aid, improve and standardise critical decision-making, based on known good practice. As mentioned in the book, the use of checklists may have fallen out of favour due to a perceived emphasis on compliance, reducing teaching to a series of "tick boxes". Blanchard, however, provides ten examples of checklists that are brief, to-the-point and simple reminders of what has been agreed and should be remembered. This is an idea that has resonated at our school and the use of "pause points" (page 157) discussed as opportunities for teachers to briefly consider what could happen prior to, during, and when concluding teaching interactions with students.

\section{About the Book Author}

John Blanchard is a former independent consultant for schools, local authorities and higher education institutions. He was a secondary school teacher and has taught on initial teacher training, bachelor's and master's programmes in education.

\section{Copyrights}

Copyright for this article is retained by the author(s), with first publication rights granted to the journal.

This is an open-access article distributed under the terms and conditions of the Creative Commons Attribution license (http://creativecommons.org/licenses/by/4.0/). 